\title{
Knowledge, Attitude and Practice Regarding Needle-Stick Injuries among Nursing Staff in a Tertiary Care Hospital, Mangalore, India
}

\author{
Amit Khelgi1 ${ }^{1}$, Rohan Raj ${ }^{2}$, Rohini Reji ${ }^{3}$, Roshni Chandran ${ }^{4}$ \\ 1,2,3,4 Nitte (Deemed to Be University), KS Hegde Medical Academy (KSHEMA), \\ Department of Microbiology, Mangalore, India.
}

\section{ABSTRACT}

\section{BACKGROUND}

Health care workers are more prone to occupational hazards, like needlestick injuries, blood, and body fluid exposures. Needlestick injuries (NSI) are responsible for the transmission of serious infections like HIV, HBV and HCV. The occurrence of needlestick injuries is highest among the nurses. The objective of the study was to assess the knowledge, attitude and practice regarding needlestick injuries among nursing faculty in Justice K. S. Hegde Charitable Hospital, Mangalore.

\section{METHODS}

A cross-sectional survey was conducted among the nursing faculty working in a tertiary care hospital based on a structured questionnaire, and the obtained data were further analysed statistically.

\section{RESULTS}

The percentage of needle stick injury was $13.3 \%$ among 75 nursing faculty. $94.7 \%$ of the nurses were aware of the universal precaution guidelines and $84 \%$ knew about post-exposure prophylaxis (PEP). $36 \%$ of nurses knew the preventive guidelines' full details, but $50.7 \%$ of the nurses were unaware of it. Many participants were aware that NSI transmits HIV (92\%) and Hepatitis B (68\%). The leading cause of NSI might be heavy work (54.7\%) followed by hurried procedures (41.3\%). $29.3 \%$ of the nurses were still inclined to recapping the needle after use. $68 \%$ of the nurses were mindful of washing hands with only water post exposure. $28 \%$ were not willing to report a NSI. $80 \%$ of nurses were fully immunised against Hepatitis B.

\section{CONCLUSIONS}

The best way to reduce NSI is to impart knowledge and awareness to the faculty. Our study showed that the knowledge, attitude, and practice among the nursing faculty were promising but requires to be further strengthened.

\section{KEY WORDS}

Needlestick Injury, Nursing Staff, Knowledge, Attitude, Practice
Corresponding Author: Dr. Amit Khelgi, Assistant professor Department of Microbiology, K. S. Hegde Medical Academy, Deralakatte, Mangalore Karnataka, India- 575180, E-mail: dramitsk14@gmail.com

DOI: $10.14260 / \mathrm{jemds} / 2021 / 468$

How to Cite This Article: Khelgi A, Raj R, Reji $R$, et al. Knowledge, attitude and practice regarding needlestick injuries among nursing staff in a tertiary care hospital, Mangalore, India. J Evolution Med Dent Sci 2021;10(30):2290-2293, DOI: $10.14260 /$ jemds $/ 2021 / 468$

Submission 20-03-2021, Peer Review 23-05-2021, Acceptance 31-05-2021, Published 26-07-2021.

Copyright (C) 2021 Amit Khelgi et al. This is an open access article distributed under Creative Commons Attribution License [Attribution 4.0 International (CC BY 4.0)] 


\section{BACKGROUND}

Needlestick injury (NSI) means penetrating stab wound, introducing blood or other potentially hazardous material into the body of healthcare worker (HCW), during the performance of their duties, by a hollow bore needle or sharp instruments including needles, lancets, scalpels. ${ }^{1}$ World Health Report 2002 states that 2 million people experience percutaneous exposure to infectious diseases each year among the 35 million healthcare workers. ${ }^{2}$ NSIs among HCWs are associated with various health hazards; the potential high-risk pathogens are the Human immunodeficiency virus (HIV), Hepatitis B (HBV) and Hepatitis C (HCV). World Health Report 2002 also noted that $37.6 \%$ of Hepatitis B, $39 \%$ of Hepatitis C and $4.4 \%$ of HIV / AIDS in health care workers worldwide were due to needlestick injuries. ${ }^{2}$ Many studies worldwide have shown that more than 35 million HCWs are facing percutaneous injuries with contaminated sharps every year. ${ }^{3}$ In India, around $3-6$ billion injections are given per year, of which two-third injections are unsafe (62.9\%), and the use of glass syringe is constantly associated with a higher degree of unsafeness. 4

Health care workers are at increased risk of acquiring blood-borne infections as they are occupationally exposed to blood and body fluids. Nurses are potentially exposed to infectious materials such as blood, body fluids, tissue, medical equipment or environmental surfaces contaminated with these substances in their workplace. They are frequently exposed to occupational hazards such as needle stick injuries, sharps injury, contact with the mucous membrane of an infected person's eyes or mouth, contact with non-intact skin exposed with blood or other potentially infectious body fluids. Nurses have been found with more needlestick injury rates among health care workers ${ }^{5}$ as they are the primary contacts with patients in a medical care setting. The lack of knowledge about NSIs and awareness of preventive measures might be one of the reasons for a higher rate of NSIs among them.

An effective infection control program requires information on occupational exposure and prevalence of the disease and its factors. Such data helps in developing and revising infection control policies and procedures. ${ }^{6}$ There is a need for such data in our institute to strengthen the infection control and prevention program. Hence, this study was done to determine the prevalence of NSIs and assess the knowledge, attitude, and practice among nursing faculty regarding NSIs in our tertiary care hospital located in Mangalore, Karnataka.

\section{METHODS}

This study was a cross-sectional survey conducted among the nursing faculty of Justice K. S. Hegde Charitable Hospital, Mangalore from April to September 2018. Institutional ethics committee clearance was obtained. The study population constituted staff nurses of the hospital who were actively involved in patient care. With reference to a previous study ${ }^{7}$ having a prevalence of NSI as $74 \%$ with $10 \%$ absolute precision \& $95 \%$ confidence level, Sample size was calculated as 74. A convenience sampling technique was done. A total of 75 nursing faculty had given consent to be part of the study. They were informed about the design and purpose of our research. The confidentiality of the participants was maintained strictly.

Data was collected using a prevalidated, structured and guided interview - based questionnaire consisting of closed and open-ended questions. A researcher was present during the survey to answer queries raised by respondents. The questionnaire included a section on demographic items such as age, gender, and work experience. Another part collected data about their vaccination status, knowledge and occurrence of NSIs, the reasons for not reporting an NSI if there was one, knowledge and practice of universal precaution guidelines, and knowledge about post exposure prophylaxis (PEP).

\section{Statistical Analysis}

The data collected was recorded and entered in an MS Excel master sheet. Data obtained were tabulated and analysed using MS Excel and SPSS version 22. Categorical data were presented as frequency and percentage. Qualitative variables were analysed using Fisher exact tests, and a P - value of $<0.05$ was considered significant.

\section{RESULTS}

All the 75 nurses included in the study were females. The mean age of the study subjects was 29.74 years (minimum age 20 years, maximum age 55 years). 10 (13.3 \%) nurses among them experienced a needle stick injury.

\begin{tabular}{|ccc|}
\hline Work Experience & Number of Nurses ( \%) & NSIs \\
$0-10 \mathrm{yrs}$ & $62(82.6)$ & 9 \\
$11-20 \mathrm{yrs}$ & $8(10.6)$ & 1 \\
$21-30 \mathrm{yrs}$ & $5(6.6)$ & 0 \\
Total & $\mathbf{7 5 ( 1 0 0 )}$ & $\mathbf{1 0}$ \\
\hline \multicolumn{3}{|c|}{ Table 1. Work Experience of the } \\
Nursing Staff and the NSIs among Them \\
(Fisher exact test $-P>0.05)$
\end{tabular}

Table 1 shows the work experience of the nurses included in the study population and the occurrence of NSIs in each age group. The majority of the nurses ( $82 \%)$ were having work experience of lesser than ten years, and similarly, the number of needle stick injuries (09) was also more among this group, but it was not statistically significant. $(\mathrm{P}>0.05)$

Table 2 shows the knowledge of the nurses about NSI. 94.7 $\%$ of the nurses were aware of the universal precaution guidelines, and $84 \%$ knew about post-exposure prophylaxis (PEP). $68 \%$ of the nurses were aware of washing hands with only water post exposure, but $5.3 \%$ thought that finger needed squeezing. $36 \%$ of nurses knew the full details of the preventive guidelines, but $50.7 \%$ of the nurses were unaware of preventive guidelines. Only $45.3 \%$ of the nurses knew the possibility of transmitting all three infections, i.e., HIV, HBV \& HCV, by NSI. A large number of participants were aware that HIV (92\%) and Hepatitis B (68 \%) were transmitted by NSI, although only $42.7 \%$ of participants knew that NSI transmitted Hepatitis $\mathrm{C}$ as well.

Table 3 shows the attitude and practices of nurses regarding NSI. $85.3 \%$ of the nurses had received formal training regarding proper handling of sharps. $86.7 \%$ used gloves as PPE while using a needle. Usage of trays to keep the sharps during procedures were seen in $96 \%$ of the nurses. $29.3 \%$ of the nurses still thought of recapping the needle after 
use. The needle stick injuries were seen in $13.3 \%$ of nurses. According to them, the leading cause of NSI was heavy work (54.7\%) followed by hurried procedure ( $41.3 \%$ ). Even though $92 \%$ thought that NSI needs to be reported, when asked whether they would report it, $28 \%$ responded negatively. When asked why they did not want to report, $40 \%$ of the nurses told NSIs due to sterile needles need not be informed, $29.3 \%$ thought reporting was not essential, and $26.7 \%$ said lack of time. $80 \%$ of the nurses were vaccinated with all the three doses of the hepatitis $B$ vaccine, and $17.3 \%$ had received at least one dose of the hepatitis B vaccine.

\begin{tabular}{|c|c|c|c|}
\hline Sl. No. & Questions & Yes N (\%) & No $N(\%)$ \\
\hline 1 & $\begin{array}{l}\text { Do you know about universal } \\
\text { precaution guidelines? }\end{array}$ & $71(94.7)$ & $4(5.3)$ \\
\hline \multirow[t]{2}{*}{2} & $\begin{array}{l}\text { Do you know about post - } \\
\text { exposure prophylaxis (PEP) }\end{array}$ & $63(84)$ & $12(16)$ \\
\hline & & Options & $\begin{array}{c}\text { Response } n \\
(\%)\end{array}$ \\
\hline \multirow{5}{*}{3} & \multirow{5}{*}{$\begin{array}{l}\text { What are the post-exposure } \\
\text { measures to be taken? }\end{array}$} & Squeeze finger & $4(5.3)$ \\
\hline & & Nothing & $1(1.3)$ \\
\hline & & Wash with water & $51(68)$ \\
\hline & & Wash with soap \& water & $17(22.7)$ \\
\hline & & Apply antiseptic / spirit & $2(2.7)$ \\
\hline \multirow{4}{*}{4} & \multirow{4}{*}{$\begin{array}{l}\text { Awareness of any preventive } \\
\text { guidelines }\end{array}$} & Know full details about them & $27(36)$ \\
\hline & & Know some details about them & $6(8)$ \\
\hline & & $\begin{array}{l}\text { Only heard about them but don't } \\
\text { know the details }\end{array}$ & $4(5.3)$ \\
\hline & & Have not heard about them at all & $38(50.7)$ \\
\hline \multirow{5}{*}{5} & \multirow{5}{*}{ Infections transmitted by NSI } & Hepatitis B & $51(68)$ \\
\hline & & Hepatitis C & $32(42.7)$ \\
\hline & & HIV & $69(92)$ \\
\hline & & All three & $34(45.3)$ \\
\hline & & None & $2(2.7)$ \\
\hline
\end{tabular}

\begin{tabular}{|c|c|c|c|}
\hline Sl. No. & Questions & $\begin{array}{c}\text { Yes } \\
\text { N (\%) }\end{array}$ & $\begin{array}{c}\text { No } \\
\text { N (\%) }\end{array}$ \\
\hline 1 & Did you receive sharps related training? & $64(85.3)$ & $11(14.7)$ \\
\hline 2 & $\begin{array}{l}\text { Do you wear gloves while using a } \\
\text { needle? }\end{array}$ & $65(86.7)$ & $10(13.3)$ \\
\hline 3 & $\begin{array}{c}\text { Do you regularly use a tray to keep } \\
\text { syringes? }\end{array}$ & $72(96)$ & $3(4)$ \\
\hline 4 & $\begin{array}{c}\text { Should the needle be recapped after } \\
\text { use? }\end{array}$ & $22(29.3)$ & $53(70.7)$ \\
\hline 5 & Any needlestick injuries to you? & $10(13.3)$ & $65(86.7)$ \\
\hline \multirow{5}{*}{6} & The leading cause of the injury & & \\
\hline & i)Heavy work & $41(54.7)$ & $34(45.3)$ \\
\hline & ii) Hurried procedure & $31(41.3)$ & $44(58.7)$ \\
\hline & iii)Lack of preventive measures & $14(18.7)$ & $61(81.3)$ \\
\hline & iv) Lack of assistance & $8(10.7)$ & $67(89.3)$ \\
\hline 7 & $\begin{array}{l}\text { Needles stick injuries needs to be } \\
\text { reported? }\end{array}$ & $69(92)$ & $6(8)$ \\
\hline 8 & Will you report NSI? & $54(72)$ & $21(28)$ \\
\hline \multirow{6}{*}{9} & Reasons for not reporting & Response n (\%) & \\
\hline & Do not think it is important & $22(29.3)$ & \\
\hline & Do not have time & $20(26.7)$ & \\
\hline & Injury due to sterile needle & $30(40)$ & \\
\hline & Do not know the reporting procedure & $2(2.7)$ & \\
\hline & Will get blamed or get in trouble & $1(1.3)$ & \\
\hline \multirow[t]{5}{*}{10} & Hepatitis B vaccination status & Response n (\%) & \\
\hline & $\begin{array}{l}\text { Received only one dose of the hepatitis } \\
\text { B vaccination }\end{array}$ & $13(17.3)$ & \\
\hline & $\begin{array}{l}\text { Received all three doses of hepatitis B } \\
\text { vaccination }\end{array}$ & $60(80)$ & \\
\hline & $\begin{array}{l}\text { Got antibody titres checked after } \\
\text { vaccination }\end{array}$ & $1(1.3)$ & \\
\hline & Did not receive Hepatitis B vaccine & $1(1.3)$ & \\
\hline
\end{tabular}

\begin{tabular}{|ccccc|}
\hline \multirow{5}{*}{ Formal Training } & \multicolumn{4}{c|}{ Kwareness of Any Preventive Guidelines } \\
& Fully & $\begin{array}{c}\text { Do Not Know } \\
\text { Fully }\end{array}$ & $\begin{array}{c}\text { Do Not } \\
\text { Know }\end{array}$ & Total \\
Received & 27 & 9 & 28 & 64 \\
Not received & 0 & 1 & 10 & 11 \\
Total & $\mathbf{2 7}$ & $\mathbf{1 0}$ & $\mathbf{3 8}$ & $\mathbf{7 5}$ \\
\hline \multicolumn{4}{|c|}{ Table 4. Nurse's Awareness of Preventive Guidelines } \\
for NSI after Formal Training \\
(Fisher exact test $p=0.007$ )
\end{tabular}

Table 4 shows the awareness regarding the preventive guidelines for NSI after formal training. Even though $85.3 \%$ of the nurses received training, $50.7 \%$ were unaware of such policies, showing a statistical significance with a P - value of 0.007 .

\section{DISCUSSION}

Occupational exposure and hazards constitute a significant concern worldwide, more so in a developing country like India. The medical faculty has constantly ignored the importance of occupational health and safety and disaster management in teaching, training and epidemiological research. Nurses have been the significant faction among the medical fraternity to experience a needle stick injury. ${ }^{5}$ In the present study, the prevalence of needlestick injuries among the nursing staff in the tertiary care hospital was $13.3 \%$. Data from the EPINet system suggests that health care workers incur approximately 30 needlestick injuries per 100 beds each year. In a study, ${ }^{8} 36$ $\%$ of health care workers had a history of needle stick injury. In their research, Gupta D et al. ${ }^{9}$ found NSIs among $69 \%$ of the nurses, which constituted $42 \%$ of nursing staff and rest were nursing students.

The significant population of nursing faculty in most healthcare facilities comprised younger nurses, as seen in many studies.8,10 A similar observation was seen in our study where $82 \%$ of the nurses had work experience of less than ten years. The knowledge regarding the universal precautions and post exposure prophylaxis was about $94.7 \%$ and $84 \%$, respectively, among the nurses of our institute, which is a good observation when compared to studies like Gurubacharya DL et al. where the knowledge regarding universal precaution was found to be $66 \%{ }^{7}$ and Gupta et al. where it was $42.5 \%{ }^{9}$ This knowledge is essential for a health care professional. It was evident in their practice as $86.7 \%$ of our hospital nurses used gloves, and $96 \%$ used sharp trays to keep syringes and needles while handling sharps during any procedures. Such practice was poorly observed in several other studies.7,9,11 Good knowledge and practice may be the reasons for less occurrence of NSIs noted in our study than others.

The responses to post exposure measure were varied, with $68 \%$ of the participants said washing with water, and $22.7 \%$ said washing with soap \& water. Similar responses were observed in the study by Sharma et al.11 Healthcare personnel should be aware of the infections which can be acquired after occupational exposure. In this study, though many participants were aware that NSI transmits HIV (92\%) and Hepatitis B (68\%), only $42.7 \%$ of participants knew that Hepatitis C could also be transmitted. Similar observations were seen in the study by Gupta et al.10 The majority of participants (54.7\%) believed that substantial work is the leading cause of NSI, as seen in another study by Sharma et al. ${ }^{12}$ with $50.4 \%$. Other reasons included hurried procedure $(41.3$ $\%)$, lack of preventive measures (18.7\%), which are in concurrence with other studies.9,12

In the present survey, $29.3 \%$ of the participants practised recapping the needle after use. Recapping has been noted as a leading cause of NSIs in several studies, 7,8,9,11,12 like in a survey by Anupriya A et al. ${ }^{12}$ recapping was done in $60.9 \%$ of NSI. According to the occupation safety and health administration (OSHA) bloodborne pathogen standard, needle recapping is strictly not advised..$^{13}$ In our study, though $92 \%$ of the subjects thought that NSIs should be reported, $28 \%$ were not ready to 
inform it. Underreporting of needlestick injuries is a common problem. In a study conducted in Massachusetts, half of all occupational NSI's were not reported; ${ }^{14}$ a similar observation was seen by Gupta et al. ${ }^{9}$

$80 \%$ of the participants had taken all three doses and 17.3 $\%$ received at least one dose of Hepatitis B vaccination as a result of a free compulsory vaccination programme for all healthcare workers conducted by hospital management. Vaccination among healthcare professionals against Hepatitis $\mathrm{B}$ as pre-exposure prophylaxis has been seriously considered in several hospitals. ${ }^{10,15}$ However, only $1.3 \%$ have got their antibody titers checked after vaccination, which is poor compared to other studies, 7,8 ranging from $14 \%$ to $18 \%$.

Sixty - four nurses in our hospital received formal training regarding sharp handling and infection prevention and control practices. It was surprising to know that even after that, at the time of study $50.7 \%$ of the nurses were unaware of preventive guidelines laid down by the hospital's infection control committee. This emphasizes that the training needs to be reinforced regularly as the nursing population changes and newer and younger nurses join the facility.

\section{CONCLUSIONS}

Needlestick injuries represent a severe occupational hazard that health care workers in hospitals face daily. The best way to reduce NSI is to impart knowledge and awareness about it. Our study showed that the nursing faculty's knowledge, attitude and practice are promising but requires to be strengthened. Reporting of sharp injuries, preventive measures and post exposure prophylaxis and follow up should be the core issues to be addressed as a part of Infection prevention and control training to all HCWs. The management should plan these as an ongoing activity in the hospital. Since this study included only a few participants, a further continuation of such surveillance activity will give a better picture.

Data sharing statement provided by the authors is available with the full text of this article at jemds.com.

Financial or other competing interests: None.

Disclosure forms provided by the authors are available with the full text of this article at jemds.com.

We are grateful to the participants and the tertiary care hospital's management authority for their kind cooperation towards the study.

\section{REFERENCES}

[1] Needlestick injuries. Bandolier Extra 2003. (cited January 23, 2008). http://www.jr2.ox.ac.uk/bandolier/Extraforbando/need le.pdf

[2] World Health Organization. Occupational healthneedlestick injuries. 2002. https://www.whi.int/occupational_health/topics/needi njuries/en/ [Last accessed on April 10 2021]

[3] Prüss-Üstün A, Rapiti E, Hutin Y. Estimation of the global burden of disease attributable to contaminated sharps injuries among health-care workers. Am J Ind Med 2005;48(6):482-90.

[4] Kermode M, Muani V. Injection practices in the formal and informal health-care sectors in rural north India. Indian J Med Res 2006;124(5):513-20.

[5] ICN on Preventing Needlestick Injuries. Nursing Matters: Fact Sheets 2009. medicalkenya.co.ke/2011/02/nursingmatters-who-fac-sheet

[6] Sahasrabuddhe AG, Suryawanshi SR, Khare R. Determinants of occupational exposure to bloodborne pathogens among resident doctors in a tertiary care hospital in the city of Mumbai. Int J Med Sci Public Health 2014;3:1014-7.

[7] Gurubacharya DL, Mathura KC, Karki DB. Knowledge, attitude and practices among health care workers on needlestick injuries. Kathmandu Univ Med J 2003;1(2):91-4.

[8] Shah R, Mehta HK, Fancy M, et al. Knowledge and awareness regarding needle stick injuries among healthcare workers in tertiary care hospital in Ahmedabad, Gujarat. National Journal of Community Medicine 2010;1(2):93-6.

[9] Gupta D, Saxena S, Agrawal VK, et al. Study of knowledge, attitude and practice of needle stick injury among nurses in a tertiary care hospital. Int J Community Med Public Health 2019;6(2):865-9.

[10] Sonia, Singh S, Singh B, et al. Study of knowledge, attitude and practice among nurses regarding needle stick and sharp item injuries. Int J Community Med Public Health 2019;6(5):2064-8.

[11] Sharma R, Rasania SK, Verma A, et al. Study of prevalence and response to needle stick injuries among health care workers in a tertiary care hospital in Delhi, India. Indian J Community Med 2010;35(1):74-7.

[12] Anupriya A, Manivelan S. KAP study on the assessment of needle stick injuries and occupational safety among health-care workers. Int J Med Sci Public Health 2015;4(3):342-5.

[13] Occupational Safety and Health Administration. Final rule on occupational exposure to bloodborne pathogens. Fed Reg 1991.

[14] Laramie AK, Davis LK, Miner C, et al. Sharps injuries among hospital workers in Massachusetts, 2010: findings from the Massachusetts sharps injury surveillance system. Massachusetts Department of Public Health 2012.

[15] Jayanth ST, Kirupakaram H, Brahmadathan KN, et al. Needlestick injuries in a tertiary care hospital. Indian J Med Microbiol 2009;27(1):44-7. 